Commentary

\title{
Lessons Learned from 55 (or More) Years of Professional Experience in Urban Planning and Development
}

\author{
Han Verschure \\ Department of Architecture, Urbanism and Planning, KU Leuven, 3000 Leuven, Belgium; E-Mail: han.verschure@kuleuven.be
}

Submitted: 30 December 2020 | Accepted: 14 January 2021 | Published: 25 May 2021

\begin{abstract}
Reflecting on the many debates over the years on changing urbanization processes, on the towns and cities of yesterday, today, and tomorrow, the main challenge will be listening to lessons of wisdom from the past and adapting these to our future professional work. When Chief Seattle said that the Earth does not belong to us, we belong to the Earth, he called for more humility and respect so as to plan for the needs of today and tomorrow, and not for the greed of a few. The doomsday scenarios of overpopulation only make sense if we continue to exploit our planet the way we do today, as if we have an infinite reservoir of resources. Already back in the 1960s, Barbara Ward, John F. C. Turner, and particularly Kenneth Boulding taught me to rethink our whole perception of Spaceship Earth. I have seen many towns and cities grow as if resources were limitless; I myself have seen and worked on efforts to focus on spatial quality, respecting nature whenever possible for a growing number of people, recognizing resources as being precious and scarce, and yet guaranteeing equitable access to a good quality of urban life. Such objectives are not evident, when models in education, schools of thought, professional planners, and greedy developers are often geared towards the contrary: the higher the skyscrapers, the better; the more egotripping by architects, the more the rich like it; the more people are stimulated to consume, the better the world will be. Such narrow visions will no longer help. At several global urban planning and developments events (1976, 1992, 1996, 2016, etc.), new ideas and agendas have been put forward. Whether the present Covid-19 crisis may induce a more rapid change in vision and practice is still too early to confirm, but luckily, several towns and cities, and a few visionary planners and decision makers are showing some promising examples.
\end{abstract}

\section{Keywords}

human settlements; international cooperation; lessons learned; planning and design; sustainability; transdisciplinarity

Issue

This commentary is part of the issue "Planning for Rapid Change in Cities" edited by Karina Landman (University of Pretoria, South Africa).

(C) 2021 by the author; licensee Cogitatio (Lisbon, Portugal). This commentary is licensed under a Creative Commons Attribution 4.0 International License (CC BY).

Considering the changing nature of international cooperation, reflecting on the lessons learned over 55 years of professional engagement in architecture, design, and spatial planning of the built environment (often named 'human settlements'), might be a good point of departure for further discussions on the topic of urban change. We will summarize the lessons learned in ten brief 'what to do' statements, each one illustrated with practical examples.

\section{Our Background Is Our Wealth and Our Limitation}

Knowing your own context is an essential precondition to be able to meaningfully and professionally communicate with others. Such background is formed over the span of several years, from childhood to adulthood, through family, friends, school, education, higher learning, travel, volunteer work, practical experience in design, construction, and built and un-built environmental planning work. Knowing your own context not only strengthens your perception of how we do things in our own context, but also how we can start to exchange experience with others in other contexts.

I was very fortunate to have had parents who let me explore, from a very early age, the city of Brussels where I was born as well as its outlying areas. I remember cycling perfectly safely at the age of six, on the broad tree-lined boulevards with designated cycling 
paths (destroyed in the 1960s, now re-planned). I visited the Brussels World Exhibit EXPO 58 frequently when I was only 15 years old and already by then having been inspired by the architectural innovations of the time. Subsequently I studied architecture and further specialized in urban design in Norway, in urban planning in Seattle, WA, and Berkeley, CA, and in environmental planning and policies in Boulder, CO. I did stints of practice and apprenticeship on construction sites and was involved in master planning in Belgium, Norway, and the US. Later, I worked on urban design and planning projects in the Middle East and internationally before joining the University of Leuven. And even while there, I continued to work in practice and to undertake a lot of fieldwork. Without this practice, both here and internationally, I would not have been able to keep one foot rooted in the practice of planning programs and projects, and one foot rooted in research, capacity building, and international cooperation.

It is important is to immerse oneself either locally or internationally in contexts where other values, religions, languages, and traditions are practiced. One should force oneself to go beyond one's own comfort zone, leave the cocoon of your own people/social class, and reach out to others, to the unknown.

\section{Learn from the Best Mentors}

Furthermore, it is clear that having inspiring mentors is vital. I have had the privilege to have internationally renowned inspirational mentors, all of whom-except the first one-I worked with or talked to personally (Chief Seattle, Christopher Alexander [see Alexander, 1979], Kennett Boulding [see Boulding, 1966], John F. C. Turner [see Turner, 1976], Paolo Soleri, Sumeth Jumsai [see Jumsai, 1988], Ivan Illich, Sulak Sivaraksa [see Sivaraksa, 2010], Balkrishna Doshi, Hassan Fathy [see Fathy, 1976], Amos Rapoport [see Rapoport, 1969], Arif Hasan [see Hasan, 2017], Elijah Agevi, Alvar Alto, John Friedmann, Ian McHarg, Bernardo Secchi, and Paola Vigano, to name just a few). Several of them came from a variety of disciplines: They were architects, planners, activists, philosophers, anthropologists, landscape urbanists, etc.

Mentors are essential to open up new ways of thinking and doing, to give you the freedom to experiment, and above all to share their unconditional wisdom, both as a person and a professional. Mentors are not there to be imitated; in fact, good mentors would always say: "Do not just do what I say or do, but explore new paths." This is important because particularly architecture and urban design is far too often an imitation of what so called 'star' architects and designers are doing. Copying from fashionable architectural magazines is the least creative process. In a rapidly globalizing world this is far too often done and only weakens the possibility to learn from other different local contexts and practices. Many schools of architecture and planning in the South unfortunately often had copy paste programs from the
North and thereby taught very little their own context and culture to their people. Although this is now gradually changing, evidently this has been a difficult basis to further understanding of local contexts. The 'Rem Koolhaases' of this world, for example, should be critically assessed. We do not want to hail ego-trippers in architecture and urban design who pretend their architecture is 'universal.'

In addition, we have to learn over time. Awareness of sustainability requirements is now greater, and also much more urgent. Many Modernist and Post-Modernist architects have yet to come to that awareness and should more humbly learn from tradition, more modestly work on a sustainable future rather than always want to be the unique stars. The slogan 'the higher the better' is a poor motivator for sustainable spatial qualities. Long-term perspectives are always necessary.

Will the 'Dubais' of this world survive or are they the ruins of tomorrow? In Dar Es Salaam, a few years ago, I was shown around a recently built high-rise building, totally inappropriately located within the urban fabric, not enhancing existing street patterns, no public space or green area around it, obscuring the harbor view for the passersby, with just a few gimmicks of colors and architectural details to make it look original-a futile and costly exercise.

The field of spatial planning is wider than architecture, but it is also often more theoretical and more recently developed. Patrick Geddes laid some of the foundation of modern planning theories and practices. Of course, throughout history there have always been urban planners. The cities of Ur, Babylon, Rome, Paris, Beijing, Great-Zimbabwe, and Cairo, for instance, had all been planned, even though with differing planning concepts.

In the more recent post-war period, Doxiadis and the Ekistics School were quite innovative for their times. They incorporated several disciplines in their 'Science of Ekistics,' dealt with a wide range of scale levels, and applied this all into many Master Plans in a number of countries.

Countries like the Netherlands had already had their first "Spatial Planning Note" from the early 1960s and have continued with revised notes regularly. Many countries in the world have continued with spatial planning efforts, although National Spatial plans are fewer than the manifold local spatial development plans.

Unfortunately, most spatial plans prepared by professionals only confirmed their subjugation to the neo-liberal systems dominating many parts of the world. They became the servants of the status quo, and were no longer the critical evaluators and innovative searchers towards a more sustainable world. Luckily, exceptions are there to prove that other paths are possible. In a recent publication edited by Louis Albrechts (2019), several decision-makers and professionals speak out on how they can make a positive difference in a changing world. 


\section{One World and Many People and Places}

Already during your young life and during your studies you have increasing opportunities to open up to the world. Youngsters nowadays travel abroad with their parents, much more than previous generations. But in doing so, they should also strengthen their observation of other cultures, not just be tourists, but young observant professionals. During studies of higher learning the opportunities for exchange have become manifold. The European Erasmus programs, for example, have proven to be very successful, not only in terms of numbers of students exchanged, but also very cost-efficient as they have opened up the world to so many young professionals at relatively little cost.

In my many years as Program Director of the Master's in Human Settlements, I have had over 450 undergraduate students who did their thesis work, most of them with several months of fieldwork, within the framework of one of our international cooperation projects in over 21 different countries. Many of these students became highly motivated and they even experienced these periods as being unique in their lives and for some, it was the start of an international professional career. These undergraduate students also learned from the many postgraduate students who came to study in Leuven, over 700 from 39 different countries over the last 25 years.

Of course, keep in mind that the world keeps changing: what one may have learned today is not necessarily valid ten years from now. As mentioned, perspectives over time are important. During intensive fieldwork in Tunisia 30 years ago, we observed, in a Muslim rural setting, that men and women live according to different rules and traditions more separated from each other, and also public space is organized accordingly. It was not up to us to change this cultural tradition. However, in contemporary urban settings in Tunisia, few elements of such traditional practice remain, and even those that do for a time period, are gradually changing under the influence of changing openness between genders. So, we do not just learn solutions for a specific moment in time, but through analysis and discussions on potential change patterns we learn to develop solutions valid for a longer time frame.

\section{Anyone, Anywhere Is A Potential Teacher or Co-Learner}

Going 'international' means having an open mind and a willingness to learn. Learning, as I have experienced over the years, one can do from anyone anywhere. Having done quite a lot of fieldwork with our team, we learned as much, or more, in the so called 'slums' - which we prefer to call popular or informal housing areas-as in some of the more highbrow formal architectural projects.

A few simple masons taught me about building with sundried earth blocks and with rammed earth in
Morocco, where I also met Elie Mouyal, a well-known architect there, who built with earth for the rich and the poor; a master builder showed me how to construct a Nubian vault in Egypt, after I had met Hassan Fathy and visited some of his work. In the late 1970s I started to cooperate with the University of Nairobi and met a Kenyan colleague there, Elijah Agevi, who knew so much about spatial planning, local housing, formal and informal, in East Africa, that I have always considered him as a mentor and invited him several times as guest lecturer and team member to Leuven. I discovered Bamboo architecture in Indonesia in remote rural villages, in the mid-1970s, and I saw how they have mastered this ancient practice, and how it can be adapted to present and future architecture even in more urbanized areas. Now a few young professionals are finally continuing on this path, but unfortunately very little is taught at schools of civil engineering worldwide.

In the 1980s, while working in the north-eastern region of Esarn, in Thailand, in collaboration with several Thai institutes, we looked into adapting traditional wood skeletons for house construction for loadbearing walls made with interlocking sundried stabilized soil blocks. Wood had disappeared because of rampant deforestation and poor people could no longer afford it. The local lateritic soil in the region was quite suitable for stabilized earth construction. Now, this method of construction is widespread and is applied widely in the region in the construction of schools, temples, water storage tanks, etc. Together with these innovations and working with the Department of Agriculture, we initiated reforestation programs to make the region less prone to drought and crop failure.

As far as construction goes, we still rely heavily on reinforced concrete construction, even though it is proven that cement production is not sustainable. In several countries, both in the Global North and Global South, it is proven that wood skeletons, for example, even for buildings as high as ten floors can be quite adequate and appropriate if the wood used is generated from reforestation programs.

Bamboo and earth are also among the several age old materials which have been rediscovered in recent decades. Similarly for public infrastructure, examples from so-called developing countries are very relevant for the North. Developed in the late 1970s, the public bus transport systems of, for instance, Curitiba in Brazil, have been far more effective than in Belgium and have inspired several cities in Latin America to prioritize the public transport needs of the wider population. Several cities in China are now developing innovative ecological parks that one can learn from. Efforts to re-plan the Mekong Delta, particularly in Vietnam-a region to become more resilient in the face of rising sea levelsare gaining recognition.

It is vital to break the limited and narrow scope of vision we often have in our own cultural worldview, and the perception of essential resources such as land, air, 
water, mineral resources, etc. In many contexts, land is a common good, so are many natural resources, not to be appropriated as fully private by individuals and exploited for private gain. We are now also increasingly seeing the limits of appropriated rights to 'private' ownership. Many resources are only borrowed from the Earth and from past generations, and we have to take good care of these for future generations. We have to re-establish the value of the 'commons,' managing land and natural resources as a community, taking care of public goods (land, forests, clean air, clean water, and seas) in a respectful and sustainable way. The list of examples is endless, and we can only be thankful to have had the opportunity to learn from so many different people.

\section{Those of Us in the Global North Are Not Superior}

I was brought up in an era when the world of the North called itself 'developed' and the South 'under-developed' (later renamed 'developing'). How erroneous this view of the world was! We in the North might have developed some technological tools that others did not have, but as far as human relations are concerned, we are no better than any other people in the world. Now, even our technological systems often malfunction due to our bureaucracy, to our lack of entrepreneurship, to our over-regulated institutions. Certainly, basic rules about fair labor, fair trade, environmental protection, human rights, etc., must be practiced, and we should propagate these, but in a globalized world we are now seeing the limits of the neo-liberal capitalist system, which often exploits natural resources to the benefit of only the rich and increases the gap between them and those who are weak, poor, and voiceless.

In terms of working towards a more sustainable world, none of us are superior; in fact, our ecological footprint in the North is far bigger than that of many other people in the South, making it far more difficult for us to change our patterns of production and consumption. It must be said that it is no longer possible to talk about the rich North and the poor South. Pockets of wealth or poverty exist in all cities, towns, and villages everywhere in the world. We cannot fight poverty without fighting excessive wealth.

\section{The Real World Is Much More Exciting than the Small Academic World}

The academic world is but a very small part of day-to-day reality. Most people do not live in this small world, often seen as an ivory tower. Indeed, that realization should make academics aware-particularly those working in international cooperation projects-of three important 'musts': First, they should explore and learn from this vast day-to-day reality, do fieldwork, and learn from practice. Secondly, they should translate their findings into understandable, user-friendly language, and communicate well with the research they do on subjects, i.e., people and communities. Researchers must never forget that the people they study give their personality and information 'on loan' to academics for study. Thirdly, the entire present system of 'publish or perish,' particularly as it is only oriented to peers, is a rather perverse system for evaluating academics. Many just publish without having anything new or meaningful to say, let alone directly involving their research subjects. In our work, we have always tried to promote the local partners we have worked with. Thesis students have been encouraged, often required, to make a presentation for the people who had been their research subjects. We have even encouraged the practice of 'revisiting projects.' One of our alumni, after having done her thesis work in a project 'Building Together' in Bangkok, returned a few years later, re-evaluated the project, stayed in contact with the dwellers and now, after many years, is still a good friend with several of them.

In terms of academic disciplines, it should be clear that ordinary people, in their day-to-day lives do not care about 'different disciplines.' They care about work that is well done and with care and attention. Separating disciplines is an academic invention. Cooperating with and transcending several disciplines is essential to work in the real world. Useful as a discipline may be in carrying out in-depth research, it more often becomes a big obstacle to the complex task of planning and building towns and villages.

Near Mwanza in Tanzania, for example, over several years, we worked in close cooperation with an anthropologist and local sociologists, to better understand the Sukuma's use of space, privacy requirements, and rituals while building their neighborhoods and villages. In Ho Chi Minch City, in Vietnam, in a major urban upgrading project lasting ten years, one of the strongest team members of the local team was an experienced sociologist.

Finally, and very importantly, we also have to work on different scales at the same time: landscapes, infrastructure patterns, nature zones, water bodies, streams and rivers, open, built and enclosed spaces, buildings, building sites and technical support, are all part of a combined human settlements approach. Separating these while planning is not contributing to a holistic qualitative outcome. An architect just designing a building on an assigned site, without questioning the assignment itself, without questioning or responding to the building's suitability in terms of its wider spatial impact, without questioning the use of materials and techniques is foregoing the essential task of a professional. Of course, questioning something has to go together with the willingness to propose alternatives. We have to be more willing to think 'outside the box' and not be afraid to work with other disciplines, to cross borders, and to dare to experiment even if there is no institutional or regulatory framework to do so. This also requires the development of a language to communicate with other disciplines and to integrate and confront different perspectives of the same reality. 


\section{Every Context Is Unique, and Cooperation and Exchange Enhance this Uniqueness}

Every context is unique; every community one works with is unique. Yet uniqueness is not a barrier to learning, communicating or exchanging. On the contrary, uniqueness offers the best opportunity not to fall into routine practice, not to rely on copycats, not to rely on fashion trends, but to explore each context and each new assignment as a unique opportunity for cooperation and exchange.

There are so many types of cooperation and partnership possible, each one with its own strengths and weaknesses. Over the years, we have undertaken many different modalities of cooperation. Cooperation with international formal institutions (e.g., UN-Habitat, UN Environment Program, UNICEF, ICLEILocal Governments for Sustainability), with international NGOs (ACHR, Habitat Coalition, SELAVIP, Protos), with universities or university networks (Asian Institute of Technology, King Mungkot University, UNPAR, ITB, HCMU, SEPT, NED, UNairobi, Ardhi/UDAR, WITS, UCT, MedCampus, ALFA, UCuenca), with local governments (Nakuru, Vinh City, Essaouira, Bayamo, Missungwi, Tarime), with local NGOs and community-based organizations in different countries, with mixed associations (government, Flemish Interuniversity Council, universities, NGOs, UN partners), and in a few cases, with commercial establishments.

It is essential to keep one's own identity clearly spelled out from the very beginning and to know one's limitations and strengths vis-à-vis the partners. Diplomacy is required but one does not have to become like the other! If cooperation among various stakeholders and partners is to be lasting and successful, then the role and the mandate of each partner should be spelled out very clearly from the outset.

Often the most rewarding types of cooperation are the relatively small scale initiatives with based on personalized working relationships. When a group of young professionals designed and built the Women's house in Ouled Merzoug, in the province of Ouerzazate, Morocco, during their Building Beyond Borders program at the University of Hasselt, of course guided by and in cooperation with local communities and artisans, they wrought long lasting relationships, and three of these young professionals are now continuing to upgrade schools in the region (Block, 2020; see also Studio Nous Nous, n.d., for another school project all with local crafts and materials, in the same region in Morocco).

Increasingly local to local cooperation is gaining strength, particularly since local authorities and local partners are the closest to their own context. In such a way, the top-down planning is slowly being reduced to its proper proportions to find a better equilibrium with more bottom-up planning. In a major program"Localizing Agenda 21"-our Post Graduate Centre for Human Settlements at KU Leuven, together with
UN-Habitat and support from the Belgian Development Cooperation, launched a localized cooperation mechanism for strategic spatial planning for better, more sustainable urban development in several medium-sized cities. Cooperation with UN-Habitat, local authorities, local communities, and experts and academic centers was challenging but successful. A major publication, "Urban Trialogues" (Loeckx, Shannon, Tuts, \& Verschure, 2004), elaborates both the theoretical foundations and the practical applications of this approach.

\section{Clarity and Honesty Will Strengthen Long-Term Engagement}

Building on the previous point, it is important to engage oneself and one's institution fully for the long term, not only in the short term like many travelling consultancy firms do. In my experience, the minimum duration for a period of cooperation was five years, sometimes even lasting more than ten years. This is definitely so for spatial planning programs that often take time to implement and come to fruition. Even architectural projects need time. One should start with the landscape planning long before a building is built. Trees take a longer time to grow but are just as essential as a building.

Only in longer term cooperation can one learn from one another and establish solid and meaningful relationships. In Nakuru (Kenya), Vinh (Vietnam), Essaouira (Morocco), and Bayamo (Cuba), we had a commitment of a minimum of five years; with UNPAR in Indonesia and with COOPIBO in Tanzania, a commitment of more than ten years; and with ACHR and SELAVIP, we have had over 30 years of ongoing cooperation.

Bringing cooperation to an end must also be carefully planned. Three of the main reasons for ending cooperation are the following. First, because of a gradual misuse of scarce resources: as an academic institution (or any organization for that matter), you have to stress that money is not the key factor of your cooperation and whatever money there is should be openly accounted for. In Indonesia, after having worked together for more than 15 years, we had to end all cooperation because of widespread misuse of resources. Secondly and very importantly, as self-reliance is a key element, one can end an ongoing cooperation because goals and objectives have been met and the local partners continue the work set out jointly in an excellent (but possibly different) manner on their own. This was the case in Cuba, South Africa, Vietnam, and Thailand. Thirdly, one can conclude that, in spite of many years of effort, results are not sufficient and do not warrant continuation, or somehow there is a divergence in objectives between the different partners. This was partially the case with Ardhi University Tanzania, and happened often when commercial interests or firms/consultants were involved in the cooperation. To conclude, the wise words from 1983 of our Pakistani colleague Arif Hasan can guide us: 
I will not do projects that will irreparably damage the ecology and environment of the area in which they are located; I will not do projects that increase poverty, dislocate people and destroy the tangible and intangible cultural heritage of communities that live in the city; I will not do projects that destroy multiclass public space and violate environment friendly bylaws and zoning regulations; and I will always object to insensitive projects that do all this, provided I can offer viable alternatives.

\section{Work towards Sustainable Development without Too Much Compromise}

The ultimate goal of all our work should be to come to a better, more qualitative sustainable built environment. This is a never-ending process and hence some will be disappointed, but in reality it is always a continuous process, a search for the better in which we can define short, to medium, to long-term objectives with well-defined steps, actions, programs, and projects. We call it a strategic process, because each project, however small or short-termed, should only be undertaken if it contributes towards this search and the defined intermediate steps towards sustainability.

For more than 50 years now, we have considered sustainability as essential, using the recommendations of the 1972 Stockholm Conference, the various UN-Habitat Conferences (e.g., in 1976, 1996, and 2016), and the Millennium Development Goals. These days, the Sustainable Development Goals provide us with even clearer goals, objectives, and action plans. The beauty of working toward sustainability is that no one can claim the ultimate solution or say: "I am there, that's it." No, our search will involve anyone, everywhere in the world, on a continuous basis. And it will definitely not be a search for the 'more' (money or material wealth) but for the 'better' (health, quality of life, freedom of expression, etc.).

Planning for sustainability is also planning for resilience, local adaptations, and transitions. Will the present pandemic teach us a lesson to focus more on essentials and less on triviality ? Personally, I find it too early to answer this question in depth. The often heard slogan "This changes everything" is too simplistic at the moment. So far, it is more likely that many decisionmakers and the better-off people worldwide consider "returning to business as usual" as their main mantra. Is that wise? No, it is not, as it indicates a reluctance to learn and adapt, but psychologically it could be understandable. In the immediate aftermath of war, it has been observed that reconstructing reality as it was is one way of overcoming destruction traumas. However, learning from changing realities seems to be one of the most difficult things for planners, as for our societies worldwide today.

The first oil crisis of 1973 was a warning; car-free Sundays were organized; people were encouraged to take public transport. Has this generated new spatial planning and architecture more focused on essential spatial qualities for the great majority of ordinary people? No, on the contrary, greed and megalomania has taken over in many cities. Freeways and car-oriented spatial planning dominate the landscape. Old bicycle paths, trees, and green spaces have been taken away to give motorized transport full priority. Many urban neighborhoods became 'dormitories to house the productive workforces.' Skyscrapers became the new model, the higher the better even with 20-storey high photos of their greedy owner embedded in the facades such as in Dubai. Pudong, China, is probably a good example. My first memory of the river site opposite Shanghai is of rice fields and a few giant billboards. Now the skyscrapers dominate, some of the older structures are dwarfed and I would add, ridiculed by these giants. Were these older villages bad? No, not at all, they were made obsolete. Later on, new villages and gated communities were planned on the Pudong side, mostly pastiche copies of Danish, British, or Spanish neighborhoods, luckily offering residential quality far better than the megalomaniac high-rise areas. The limitations of Spaceship Earth are as yet to be changing the behavior of many, particularly in the many rich pockets of our world, the large greedy enterprises and the wealthy.

\section{Never Forget the Past in Planning for the Future}

Let me conclude with a last, short lesson learned. We are but a short moment on Earth, so we have to remain modest and know that many, many generations before us have planned and built human settlements and used planning and construction techniques and practices that evolved over many generations and were adapted to local cultures and local resources. Recent globalization did away with some of these modes of planning and building and many new typologies of built environments emerged. In addition-and this remains one of the biggest problems today-the Modernist movement in Architecture and Urbanism wanted to start from a clear slate, as if the past was not there. Le Corbusier presented a new plan for Paris (luckily this has never been implemented), after Haussmann had already destroyed old neighborhoods. Housing became a 'machine to live in,' superblocks emerged as prototypes, putting people into industrialized prefab boxes (like 'sardines'). The new modes of Modernist motorized transport, for example, altered the city and landscape infrastructure and layout. We now see the limits of such a car-oriented approach. Walking and cycling have become more important modes of transport, so we have to rethink and re-plan our streets, public buildings, green and open spaces, housing and service facilities. Adapting to local culture, climate, and resources was often an afterthought among urbanists, and it unfortunately still is, among most of the very greedy project developers, disregarding fundamental concepts of sustainable development. Such developers now by far dominate over 
powerless (or disinterested/corrupted) public authorities, backed by unscrupulous professionals. This must and will change. So let us conclude with an optimistic look towards the future. The younger generation will have to be called upon. If they have the courage and the vision, the younger generations (can) have the power, (can) have the spirit, and (can) have the awareness. And several of us of older generations are there to back this new generation:

Finally, as a junior urban scholar, it strikes me that the role of geographers and planners has been primarily that of audiences during this outbreak. Various Chinese urban scholars expressed disappointment about their limited ability to make contributions to this war against the coronavirus, while witnessing how other professionals are more actively involved. To me, the epidemic also raises questions about how urban scholars could position ourselves in an epidemic. Urban planners, who have long been positioned to deal with uncertainty and to mediate between authorities and publics, might be well positioned to work with other stakeholders on an epidemic-response system that builds a collaborative framework among different sectors, smoothens the information flow between experts and people, and helps city governments to deal with uncertain developments of the outbreak. (Hang, 2020)

\section{Acknowledgments}

This commentary is a much expanded version of a lecture with PowerPoints given for postgraduate and mid-career professionals at the end of an intensive International training program in late 2019. With great thanks to Mrs. Joohi Haleem for the English language corrections.

\section{Conflict of Interests}

The author declares no conflict of interests.

\section{References}

Albrechts, L. (Ed). (2019). Planners in politics: Do they make a difference ? Cheltenham: Edward Elgar Publishing.

Alexander, C. (1979). The timeless way of building. Oxford: Oxford University Press.

Block, I. (2020). Building Beyond Borders uses stone and earth to build Women's House Ouled Merzoug. Dezeen. Retrieved from https://www.dezeen.com/ 2020/04/24/building-beyond-borders-womenshouse-ouled-merzoug

Boulding, K. (1966). The economics of the coming Spaceship Earth. In H. Jarrett (Ed.), Environmental quality in a growing economy (pp. 3-14). Baltimore, MD: Johns Hopkins University Press.

Fathy, H. (1976). Architecture for the poor. Chicago, IL: University of Chicago Press.

Hang, M. (2020). Preparing cities for epidemics: Lessons from the COVID19 outbreak. International Journal of Urban and Regional Research. Retrieved from https://www.ijurr.org/the-urban-now/preparingcities-for-epidemics

Hasan, A. (2017). Drivers of climate change vulnerability at different scales in Karachi (IIED Working Paper). London: IIED.

Jumsai, S. (1988). Naga: Cultural origins in Siam and the West Pacific. Oxford: Oxford University Press.

Loeckx, A., Shannon, K., Tuts, R., \& Verschure, H. (Eds.). (2004). Urban trialogues: Visions, projects, coproductions. Localizing Agenda 21. Nairobi: United Nations Centre for Human Settlements

Rapoport, A. (1969). House form and culture. Princeton, $\mathrm{NJ}$ : Pearson Education.

Sivaraksa, S. (2010). The wisdom of sustainability: Buddhist economics for the 21st century. Bangkok: Souvenir Press.

Studio Nous Nous. (n.d.). Homepage. Studio Nous Nous. Retrieved from https://www.studionousnous.org

Turner, J. F. C. (1976). Housing by people: Towards autonomy in building environments. London: Marion Boyars.

\section{About the Author}

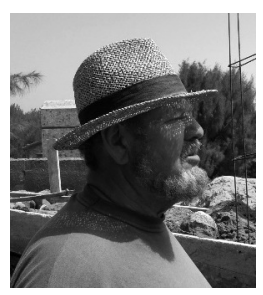

Han Verschure is Professor Emeritus in Human Settlements, Architecture, and Spatial and Environmental Planning at KU Leuven, and an Expert Advisor in Development and Cooperation Programmes with international organizations, universities, national and local authorities, communitybased organizations, and NGOs. He has over 55 years of professional experience and is a pioneer in sustainable development and follow-up of programmes and projects, training and capacity building, policymaking, and research, in the domains of habitat, sustainable urban and rural settlement development, sustainable building and locally appropriate construction, urban renewal and heritage conservation, spatial and environmental planning, planning after disasters and emergency aids programmesparticularly but not exclusively-in over 28 developing countries, such as Haiti, Nepal, Kenya, Tanzania, Vietnam, Thailand, Cuba, Ecuador, etc. 